TITLE:

\title{
Synchronized hatching as a possible strategy to avoid sibling cannibalism in stink bugs
}

\author{
$\operatorname{AUTHOR(S):~}$ \\ Endo, Jun; Numata, Hideharu
}

\section{CITATION:}

Endo, Jun ...[et al]. Synchronized hatching as a possible strategy to avoid sibling cannibalism in stink bugs. Behavioral Ecology and Sociobiology 2020, 74: 16.

\section{ISSUE DATE:}

2020-01-14

URL:

http://hdl.handle.net/2433/245875

\section{RIGHT:}

This is a post-peer-review, pre-copyedit version of an article published in Behavioral Ecology and Sociobiology. The final authenticated version is available online at: $\mathrm{http}: / / \mathrm{dx}$.doi.org/10.1007/s00265-020-2799-0.; The full-text file will be made open to the public on 14 January 2021 in accordance with publisher's 'Terms and Conditions for Self-Archiving'.; This is not the published version. Please cite only the published version.; この論文は出版社版でありません。引用の際

には出版社版をご確認ご利用ください。 
Synchronized hatching as a possible strategy to avoid sibling cannibalism in stink bugs

Jun Endo ${ }^{1}$, Hideharu Numata ${ }^{1}$

1 Graduate School of Science, Kyoto University, Sakyo, Kyoto 606-8502, Japan

Correspondence: Hideharu Numata

E-mail address: numata@ethol.zool.kyoto-u.ac.jp

Tel: $+81-75-753-4073$

ORCID:

H. Numata: 0000-0003-3786-0701 


\section{Abstract}

In some animals, timing of egg hatching is adjusted in response to cues from clutch mates to synchronize hatching within a clutch and this typically facilitates mass migration of hatchlings from their natal clutch. A recent study in eight species of Pentatomidae revealed that four species show synchronized hatching due to responses to earlier-hatched siblings, by comparing temporal hatching patterns between intact clutches and eggs individually detached from clutches. However, hatchlings of Pentatomidae do not migrate from their natal clutch immediately. In the present study, using the same eight species, we explored the evolutionary reason for the synchronized hatching in Pentatomidae. In all of the species examined except one non-synchronized species, Eurydema rugosum, hatchlings showed egg feeding behavior with greatly different time of onset. The highly synchronized species, Halyomorpha halys and Nezara viridula, had the time of onset of egg feeding earlier than in the other species. In these two species, based on the hatching patterns of eggs individually detached from their clutches, we concluded that eggs can be cannibalized by their earlier-hatched siblings unless they hatch in response to siblings. On the other hand, this was not the case in the moderately synchronized species, Piezodorus hybneri and Plautia stali. In the other three non-synchronized species, Aelia fieberi, Dolycoris baccarum, and Palomena angulosa, eggs seemed not to incur a risk of cannibalism. In intact $H$. halys clutches, almost no eggs were cannibalized by siblings. In conclusion, synchronized hatching serves as a possible strategy to avoid sibling cannibalism in Pentatomidae, although it can also have some other functions.

\section{Significance statement}


Eggs should often be able to control when to hatch in response to environmental factors affecting survival of eggs or hatchlings. Species of various taxa show responses to siblings in the same clutch to achieve synchronized hatching among the siblings. It is typically recognized that such synchronized hatching is required so that hatchlings leave their natal clutch together, which serves, for example, to reduce the risk of being preyed on by predators. Here, we present evidence supporting that synchronized hatching observed in some stink bugs helps eggs to avoid being cannibalized by their earlier-hatched siblings. We also show that other stink bugs with no synchronized hatching have no or little risk of sibling egg cannibalism. This study deepens our knowledge that the synchronized hatching can function in various social contexts with siblings.

Keywords Avoidance of cannibalism · Halyomorpha halys · Nezara viridula · Pentatomidae $\cdot$ Sibling cannibalism $\cdot$ Stink bug $\cdot$ Synchronized hatching 


\section{Introduction}

In many animals, timing of egg hatching is adjusted in response to cues from environmental factors affecting survival of eggs or hatchlings, such as seasonal or diel changes, flooding, parents, or predators (Warkentin and Caldwell, 2009; Warkentin, 2011). Species laying clutches of eggs can have responses to clutch mates for achieving synchronized hatching within a clutch (Warkentin and Caldwell 2009). Such responses are known in various taxa including birds, reptiles, and insects, and are typically recognized as means for hatchlings to leave their natal clutch together (Provine 1976; Woolf et al. 1976; Spencer et al. 2001). In a turtle, for example, synchronized hatching facilitates mass migration of hatchlings, reducing the risk of being preyed on by predators and energy loss during nest emergence (Spencer et al. 2001). On the other hand, recent studies in two other turtles indicate that synchronized hatching allows eggs to hatch without lags after siblings in competition for overwintering positions within the nest (Colbert et al. 2010) or after siblings that hatched earlier in response to and for avoiding nest flooding (Doody et al. 2012). Thus, there is increasing evidence that synchronized hatching is needed in various contexts in early lives with siblings, and its function or necessity can vary even among related species.

Previous studies in a few species of the stink bug family Pentatomidae (Heteroptera) indicated that hatching is synchronized within a clutch as a result that unhatched nymphs respond to cues from their clutch mates (Morimoto 1965; Lockwood and Story 1985). In this family, a clutch is typically composed of eggs densely laid on a plant surface and includes individuals which are full-siblings or half-siblings because multiple copulation is common (e.g., H. halys: Kawada and Kitamura 1983). Recently 
we examined whether and to what extent responses to siblings synchronize hatching within a clutch in eight species of the family: In Halyomorpha halys, Nezara viridula, Piezodorus hybneri, and Plautia stali, intact clutches hatched in significantly more synchronized manners when compared to eggs individually detached from clutches. Especially, $H$. halys and $N$. viridula showed highly synchronized hatching patterns. In the other species examined, Aelia fieberi, Dolycoris baccarum, Eurydema rugosum, and Palomena angulosa, hatching of intact clutches was not significantly more synchronized (Endo and Numata 2017). Thus, temporal hatching patterns in Pentatomidae vary from non-synchronized to highly synchronized ones. In $H$. halys, the cues for hatching are single pulsed vibrations generated when siblings crack open their eggshells (Endo et al. 2019). The variation in the hatching patterns can be proximately caused by various factors, such as cue types, responsiveness, and transmission (Endo and Numata 2017). A remaining question is the evolutionary reason(s) of the synchronized hatching. Hatchlings of this family, even in species with synchronized hatching, usually do not move away from their natal clutch soon after hatching but form a dense aggregation that persists for a few days closely around it (Kiritani 1964). Accordingly, it is unlikely that the synchronized hatching observed in some species is required for mass migration of hatchlings from their natal clutch.

The synchronized hatching may be related to sibling cannibalism, in which hatchlings eat eggs in the same clutch. Sibling cannibalism is very common in animals with grouped offspring (Polis 1981; Elgar and Crespi 1992). Although the cannibalism can carry some costs, including a loss of inclusive fitness, it is often adaptive because the cannibals in general have increased survival owing to the resulting rich nutrients and reduced competition (Eickwort 1973). Evolutionarily, victims of the cannibalism can 
also benefit from the increased survival of their kin. However, the cannibals require less survival increase to get net benefits from the cannibalism than do the victims because the cannibals are genetically more related to themselves than to the victims (O'Connor 1978; Mock and Parker 1997). Where sibling cannibalism is adaptive only for the cannibals, possible victims may use mechanisms to avoid it. Chemical defense is known to protect eggs against cannibalism by earlier-hatched clutch mates: In a leaf beetle, due to this defense, the actual proportion of egg cannibalism seems to be much lower than the potential level (Kirk 1988). It is also possible that eggs may avoid cannibalism by earlier-hatched siblings through sibling-cued synchronized hatching; the eggs will not be eaten if they hatch before the cannibalism starts. A mother of eggs is known to control the temporal hatching pattern of her eggs to affect the occurrence of sibling cannibalism in birds (Stoleson and Beissinger 1995) and in insects (Crespi 1992; Dickinson 1992; Perry and Roitberg 2005). For example, a mother of a green lacewing, by responding to low prey availability, enhances the dispersion of hatching times among eggs, perhaps through modifying oviposition interval or yolk content. Then, hatchlings have more chance to cannibalize sibling eggs, resulting in better offspring survival. In food-rich conditions, she reduces the dispersion of hatching times and thereby prevents excessive cannibalism (Fréchette and Coderre 2000). On the other hand, there is no evidence that eggs actively control the temporal hatching pattern of a clutch to affect the occurrence of the cannibalism. In Pentatomidae, Endo and Numata (2017) previously reported that hatchlings of some of the above species feed on eggs, if any remain in their natal clutches. In the present study, therefore, we hypothesize that, in some species of Pentatomidae, the synchronized hatching in response to siblings has evolved to avoid sibling egg cannibalism. That is, their nymphs often cannot emerge from their eggs 
before egg feeding starts in their clutch if they do not hatch by responding to their siblings. To test this possibility, we first examine the time until the first egg feeding behavior is observed in a clutch (the time of onset of egg feeding) in the eight species used by Endo and Numata (2017) with differently synchronized hatching patterns. Then, we evaluate whether eggs of the synchronized species (H. halys, N. viridula, Pi. hybneri, and Pl. stali) incur a risk of cannibalism unless they show hatching responses, and whether eggs of the non-synchronized species (A. fieberi, D. baccarum, E. rugosum, and $\mathrm{Pa}$. angulosa) have no risk of cannibalism.

\section{Materials and methods}

\section{Insects and egg clutches}

Adults of A. fieberi, D. baccarum, E. rugosum, $H$. halys, $N$. viridula, Pa. angulosa, Pi. hybneri, and Pl. stali were collected from the field in Kyoto, Osaka and Hyogo Prefectures, Japan, in 2014-2016. To obtain egg clutches, these adults were maintained under a $16: 8 \mathrm{~h}$ light:dark cycle at $25 \pm 1{ }^{\circ} \mathrm{C}$ in plastic cups, where they were provided with water and oviposition sites made of drawing paper. Foods were supplied as previously reported (Endo and Numata 2017). Egg clutches were collected with their oviposition substrates within $24 \mathrm{~h}$ of oviposition. Eggs were kept at $25^{\circ} \mathrm{C}$ and $80 \%$ or higher relative humidity unless otherwise noted. Clutches with particular size ranges were used as in Endo and Numata (2017): $12 \pm 2$ for A. fieberi and E. rugosum; $14 \pm 2$ for Pa. angulosa and Pl. stali; $28 \pm 4$ for D. baccarum, H. halys, and Pi. hybneri; and 84 \pm 13 for $N$. viridula. These ranges closely correspond to frequently observed clutch 
sizes in these species (J. Endo and H. Numata, personal observation).

\section{Time of onset of egg feeding}

To examine time of onset of egg feeding, we created conditions under which the first-instar nymphs could eat sibling eggs at any time after hatching, by delaying embryonic development in a small portion of eggs within a clutch as follows: Within 54 $\mathrm{h}$ of collection of a clutch, eggs constituting approximately $15 \%$ of the clutch size were detached from the periphery of the clutch using a razor blade and forceps under a stereomicroscope (S8 APO; Leica Microsystems, Wetzlar, Germany). These eggs were transferred to $10 \pm 1{ }^{\circ} \mathrm{C}$ to retard their development, and then returned to the original clutch kept at $25^{\circ} \mathrm{C}$ within 2 days before the clutch's estimated hatching onset. For convenience of observation, the eggs were arranged at nearly equal distances from each other at the periphery of the egg clutch using starch glue. A treated clutch was fixed with double-stick tape on the bottom of a clear plastic case $(36 \times 36 \mathrm{~mm}$, height $14 \mathrm{~mm})$ containing wet cotton. The clutch was photographed every 5 min from the top view with a digital camera (CX6; Ricoh, Japan or P310; Nikon, Tokyo, Japan) since before their hatching. It is reported that, in some species of Pentatomidae, including $H$. halys, the nymphs roam on the clutch immediately after hatching to acquire bacterial symbionts (Calizotti and Panizzi 2014; Taylor 2016). We recorded behavior of first-instar nymphs until they started egg feeding after the roaming behavior by photographs. At the beginning of the egg feeding, a first-instar nymph held a victim egg and, as the nymph sucked the pigmented egg contents in the eggshell, the egg became dented or changed its color, or both. The time of the first egg holding behavior that resulted in such egg 
changes was examined during $24 \mathrm{~h}$ after the first hatching using the photographs, and this time was defined as the time of onset of egg feeding.

\section{Frequency of sibling egg cannibalism in $H$. halys}

To test whether eggs of $H$. halys avoid sibling cannibalism in intact clutches, nine female/male pairs were individually kept in a plastic cup, and egg clutches were collected for 20 days after the first oviposition of fertilized eggs. One or two days before the estimated hatching date of a clutch, egg development was evaluated for each of the eggs by judging whether compound eyes and an egg burster (T-shaped, cuticular structure for cracking open an eggshell) were observed through the operculum of the eggshell. Nymphs aggregating on it were removed 24-48 $\mathrm{h}$ after hatching of a clutch, and the internal unhatched eggs were inspected for traces of egg feeding.

\section{Nutritional effects of egg feeding in $H$. halys}

To examine how egg feeding affects $H$. halys nymphs nutritionally, growth and survival were compared between individuals that ate a single sibling egg soon after hatching (treatment group) and those that ate no eggs (control group). Eggs of seven clutches were individually detached on the collection day, and, for each clutch, approximately two-thirds of the eggs were allocated to obtain nymphs for the test and the others to provide nymphs of the treatment group (food eggs). The latter eggs were kept at $10^{\circ} \mathrm{C}$ to retard their development. The former eggs were individually fixed on a piece of drawing paper $(15 \times 15 \mathrm{~mm})$ using starch glue and kept at $25^{\circ} \mathrm{C}$. After hatching 
of these eggs, some nymphs were allowed to consume a single food egg that had been fixed close to them 1 day before the hatching. The other nymphs were not provided with food eggs. From the former group (a total number of 61), 39 nymphs that actually consumed the food egg by the day after hatching were selected for the treatment group. From the latter group (a total number of 52), 36 nymphs were randomly selected for the control group, so that nearly the same number of nymphs from each clutch were included in the two groups. From each of the seven clutches, three to eight nymphs were included in each of the group.

Nymphs were individually reared in a small cylindrical plastic case $(86 \mathrm{~mm}$ diameter, $40 \mathrm{~mm}$ depth) at $25^{\circ} \mathrm{C}$. Wet cotton was provided as a water source from 1 day before hatching and half of a cut, raw peanut was supplied at 2-4-day intervals starting from the day after hatching. Developmental stages of the nymphs were examined daily until adult emergence or the 72nd day after hatching. All individuals that survived more than 72 days as nymphs died in the final (5th) instar. The sex and body weight were examined on the day of adult emergence.

\section{Statistical analyses}

All statistical analyses were conducted in R (ver. 3.3.2). The Kruskal-Wallis test followed by the Steel-Dwass post-hoc test was used to compare the time of onset of egg feeding among species examined. The Mann-Whitney $U$ test was used to compare the nymphal duration and adult body weight between the nymphs that ate a single egg and those that ate no eggs. Their mortality was compared by Fisher's exact test. 


\section{Data availability}

The datasets analyzed during the current study are available from the corresponding author on reasonable request.

\section{Results}

\section{Egg feeding by newly hatched nymphs}

We observed, in the eight species, behavior of first-instar nymphs until they started egg feeding after hatching. In all of the species examined except E. rugosum, we observed that newly hatched nymphs ate sibling eggs that were from their natal clutch and had artificially delayed development. However, the time of onset of egg feeding was substantially different among the seven species (Fig. 1). In highly synchronized species, $H$. halys and $N$. viridula, the median time of onset of egg feeding tended to be earlier than that in the other species, although the difference was not statistically significant between $N$. viridula and Pa. angulosa or between $N$. viridula and Pi. hybneri. Egg feeding was always observed in the seven species except in A. fieberi, in which it occurred in only 6 of 11 clutches.

Fig. 2 shows behavioral sequences of newly hatched nymphs of $H$. halys and Pa. angulosa. We observed that, in all the species examined, nymphs roamed on their clutch after hatching (H. halys, Fig. 2b; Pa. angulosa, Fig. 2g). Then, the nymphs did not disperse but settled in close to their clutch, and became motionless (H. halys, Fig. 2e; Pa. angulosa, Fig. 2h). They sometimes resumed roaming almost simultaneously 
and then became motionless again. In some or all clutches of Pi. hybneri, Pl. stali, A. fieberi, D. baccarum, and Pa. angulosa, egg feeding started when the nymphs resumed roaming after all the nymphs within the clutch became motionless at least once for 5 min (Pa. angulosa, Fig. 2h, i). In H. halys and N. viridula, however, egg feeding always started during the initial roaming process before the nymphs first became motionless $(H$. halys, Fig. 2c-e).

\section{Risk of sibling egg cannibalism}

Fig. 1 presents, in the eight species, the relationship between the time of onset of egg feeding revealed in the present study and temporal hatching patterns of intact clutches and eggs individually detached from clutches described by Endo and Numata (2017). Based on this relationship, we evaluated, in the four synchronized species, whether an egg incurs a risk of being eaten by earlier-hatched siblings if it does not hatch in response to its siblings. We used the probability that an egg without a hatching response remains unhatched at the onset of egg feeding, which is expected to coincide with the rate of unhatched eggs within eggs detached from clutches at the same time.

In highly synchronized species, $H$. halys and $N$. viridula, the egg seems to incur a high risk of the cannibalism because the hatchlings start egg feeding early: At the median value of the time of onset of egg feeding, the probability that an egg without a hatching response remained unhatched was $57.1 \%$ and $51.9 \%$ (median) in $H$. halys and N. viridula, respectively. In moderately synchronized species, Pi. hybneri and Pl. stali, however, this probability was $0 \%$ and, therefore, the risk of the cannibalism seems to be very low even if the egg does not show a hatching response. In H. halys and N. viridula, 
almost all the eggs in intact clutches were estimated to hatch before the onset of egg feeding (Fig. 1). Accordingly, we concluded that eggs of H. halys and N. viridula can mostly prevent the risk of the cannibalism if they hatch in response to siblings. Also in clutches of non-synchronized species, A. fieberi, D. baccarum, E. rugosum, and Pa. angulosa, it seemed that eggs incurred little or no risk of cannibalism because almost all the eggs were estimated to hatch before the onset of egg feeding (Fig. 1). We observed no egg feeding in E. rugosum in this experiment.

\section{Cannibalism frequency in $H$. halys}

The above results indicate that eggs of $H$. halys and $N$. viridula avoid sibling cannibalism in intact clutches. To obtain support for this, we examined the actual frequency of cannibalism in $H$. halys using 24 clutches with a size range of $28 \pm 4$ eggs (660 eggs in total). In conclusion, in these clutches, normally developed eggs were seldom cannibalized by hatched siblings, although the nymphs ate most of the eggs that did not develop normally and thus did not synchronize hatching with their clutch mates. The details were as follows: In 5 of 24 clutches, $1-5$ eggs (12 eggs in total, 1.8\%) were cannibalized by adults before collection. When these eggs were excluded, the proportion of normally developed eggs per clutch was $96.4 \%$ (median, first quartile $\left[Q_{1}\right]$ $=94.8$; third quartile $\left.\left[Q_{3}\right]=100\right)$ and, in the 24 clutches, 614 normally developed eggs were contained in total. There were 34 eggs in total that did not develop normally (1-10 eggs in 13 clutches). Among them, 33 eggs (97.1\%) were eaten by hatched siblings. In contrast, among the 614 normally developed eggs, the number of victims of sibling egg cannibalism was only 9 (1.5\%, 1-3 eggs in 5 clutches). 


\section{Nutritional effects of egg feeding in $H$. halys}

The above results indicate the possibility that highly synchronized hatching of $H$. halys and $N$. viridula is a strategy to avoid cannibalism by egg feeding. To get insight into the evolution of the highly synchronized hatching and the egg feeding, as a case study, we examined whether and how the egg feeding of $H$. halys benefits the nymphs nutritionally. We compared the growth and survival between the individuals that fed on a single egg soon after hatching (treatment group) and those that did not feed on any eggs (control group). Fig. 3 shows the duration of nymphal instars in the two groups for individuals that emerged as adults. Within each experimental group, because no significant sexual differences were detected in the duration of each instar (Mann-Whitney $U$ test: $P>0.1$ ), the data on females and males were combined. In the first instar, median duration of this period was 5 days in both control and treatment group. However, approximately $40 \%$ of nymphs in the treatment group had a shorter duration of 4 days and the duration of the first instar was significantly shorter in this group (Mann-Whitney $U$ test: $U=496, P<0.001$ ). The durations of the second to fifth instar and total nymphal period did not differ significantly between the two groups (Mann-Whitney $U$ test: $P>0.05$ ). However, although a small fraction of nymphs had prolonged durations of the fourth or fifth instar in the control group, such a tendency was not observed in the treatment group. The mortality did not differ significantly between the groups for each instar (Fisher's exact test: $P>0.05$ ). The total mortality was $30.6 \%$ and $28.2 \%$ in the control and treatment groups, respectively. Adult body weight also was not significantly different between the two groups for either sex 
(Mann-Whitney $U$ test: females: $U=51, P=0.37$; males: $U=69, P=0.08$ ). Median body weight of females and males was $0.177 \mathrm{~g}\left(Q_{1}=0.156 ; Q_{3}=0.223, N=12\right)$ and $0.143 \mathrm{~g}\left(Q_{1}=0.119 ; Q_{3}=0.153, N=13\right)$ in the control group, and $0.207 \mathrm{~g}\left(Q_{1}=0.186\right.$; $\left.Q_{3}=0.214, N=11\right)$ and $0.152 \mathrm{~g}\left(Q_{1}=0.142 ; Q_{3}=0.158, N=17\right)$ in the treatment group, respectively. Collectively, $H$. halys nymphs that consumed a single egg soon after hatching seem not to gain clear nutritional benefits but show decrease in the duration of the first instar.

\section{Discussion}

\section{Synchronized hatching as a possible strategy to avoid egg cannibalism}

In the present study, we expected that eggs of some stink bugs (Pentatomidae) can be cannibalized by earlier-hatched clutch mates if there is no synchronizing of hatching in response to the earlier-hatched clutch mates. We can consider that, in general, each egg in a clutch has its own spontaneous hatching time with a certain distribution. Eggs with late hatching times have a risk of cannibalism if hatchlings cannibalize eggs. Kutcherov (2015) presumed that, in such cases, because hatching as early as possible is advantageous both from the standpoint of obtaining eggs and avoiding cannibalism, the distribution of spontaneous hatching times becomes so small that all eggs within a clutch hatch before the cannibalism starts. However, our data obtained here indicated that, in H. halys and N. viridula, approximately half of eggs in the clutch have spontaneous hatching times later than the onset of egg feeding, and thus could potentially be cannibalized. In intact clutches of both species, in which hatching is 
highly synchronized due to responses to sibling cues, we estimated also that almost all the eggs hatch before hatchlings start egg feeding. Actually, in H. halys, most of the normally developed eggs in intact clutches succeeded to hatch without being eaten. Accordingly, we can consider that the highly synchronized hatching of both species has evolved as a strategy to avoid sibling cannibalism, although other evolutionary scenarios cannot be excluded, as discussed below. It is known that, in some cases, sibling-cued synchronized hatching imposes costs because it is done by hatching prematurely (Colbert et al. 2010). On the other hand, H. halys and $N$. viridula advance their hatching times by only a few hours to achieve the synchronized hatching (Endo and Numata 2017). Therefore, presumably, H. halys and N. viridula can synchronize hatching and avoid the cannibalism at a slight cost.

It has been recognized that a mother can affect the occurrence of sibling cannibalism by controlling the temporal hatching pattern of her eggs to maximize the number of offspring (Crespi 1992; Dickinson 1992; Stoleson and Beissinger 1995; Perry and Roitberg 2005). This study first provides experimental evidence that eggs actively control their hatching time in response to siblings to have an impact on the occurrence of the cannibalism. To our knowledge, this idea was first proposed in a study in a locust, where the synchronized hatching may prevent cannibalism of later-hatching nymphs (Nishide and Tanaka 2016). We expect that, in many insect groups, potential victims of sibling egg/larval cannibalism control the temporal hatching pattern of a clutch, and thus reduce the risk of being eaten. In a subsocial burrower bug, Adomerus rotundus (Heteroptera: Cydnidae), hatching is synchronized within a clutch as a result that eggs hatch in response to vibrations generated by a mother (Mukai et al. 2012); also, the times of the first molt are synchronized among the offspring, and this mitigates the 
risk of cannibalism during a defenseless period just after the molting (Mukai et al. 2018). This case is interesting in that both the maternal control and egg responses affect the temporal hatching pattern and occurrence of the cannibalism.

\section{Costs and benefits of egg cannibalism}

We suppose that early egg feeding of $H$. halys and $N$. viridula has evolved to prey on later-hatching siblings. In general, killing viable siblings imposes costs on cannibals: It not only causes a loss of inclusive fitness but also can reduce benefits of group living (Stevens 1992). In Pentatomidae, the first-instar nymphs maintain aggregation close to their natal clutch for a certain period (Kiritani 1964). This aggregation provides protection against low temperature, desiccation, predators, and dropout from plants (Lockwood and Story 1986). In and after the second instar also, the nymphs live more or less in groups on food plants (Hokyo and Kiritani, 1962), and this also helps survival and growth (Kiritani 1964; Kiritani and Kimura 1966; Kiritani et al. 1966; Nielsen et al. 2008). Sibling cannibalism probably reduces these positive effects of group living in Pentatomidae.

We can expect that, in $H$. halys and $N$. viridula, the cannibalism on viable sibling eggs provides benefits that cover its costs. The most obvious benefit of cannibalism is acquisition of additional food (Polis 1981). In the present study, to obtain clues for understanding the evolution of the early egg feeding, we examined its nutritional benefits in $H$. halys. In insects, many studies have revealed that larvae given conspecific eggs as well as normal diet have nutritional advantages, such as increased adult weight and decreased developmental time and mortality over the immature period 
(Osawa 1992; Michaud and Grant 2004; Collie et al. 2013; Gomi et al. 2015). However, in the present study, $H$. halys nymphs that ate a single sibling egg did not have clear advantages like these. As we discuss below, it is possible that the egg feeding provides benefits that cannot be confirmed in the present experimental conditions. We should note that we reared the nymphs in individuals, not in a group. This may possibly have affected the growth of the nymphs negatively and thereby partially concealed an increase in the growth by the cannibalism. Tests with a group-rearing are needed for better understanding of the effects of the cannibalism on the growth.

In some insects, the first instar larvae take a long time to obtain food, and sibling egg cannibalism prevents their starvation during this period by supplying energy (Kawai 1978; Gomi et al. 2015). Our data indicated that the cannibalism in H. halys reduces the duration of the first instar. Based on this, we may be able to assume that the egg cannibals have an energetic advantage in their early life stages. Because first-instar nymphs of Pentatomidae typically require only water for molting to the next instar (e.g., N. viridula: Kiritani 1964; Lockwood and Story 1986), H. halys nymphs seem not to suffer starvation risk in the first instar. However, they may suffer it in the second instar and later, because they are sometimes observed dispersing over long distances to other host plants to obtain fruits or seeds required for their growth (Lee et al. 2014; Acebes-Doria et al. 2016a, b). The dispersing early-instar nymphs may improve their survival by the egg cannibalism. In general, cannibalism can also be beneficial because it reduces future competition for food resources (Polis 1981). It is known that this is the case in some herbivorous insects of which the larvae are confined to a limited food resource (Richardson et al. 2010). However, it is unclear that $H$. halys nymphs with the dispersal tendency profit from reduced competition. At present, in $N$. viridula, we do not 
have any information about how the egg feeding affects the nymphs, but its benefits may differ from those in $H$. halys because second-instar nymphs of $N$. viridula seem not to move far away from their natal clutch (Todd 1989).

\section{Interspecific variation and evolution of synchronized hatching patterns}

Egg feeding starts earlier in the highly synchronized species than in non-synchronized species, A. fieberi, $D$. baccarum, and Pa. angulosa, and no egg feeding was observed in E. rugosum. More importantly, only in the highly synchronized species, egg feeding starts early enough to impose an obvious risk of cannibalism on the eggs without a hatching response. Therefore, we can consider that, in Pentatomidae, synchronized hatching may have evolved in association with the early onset of egg feeding in some cases. Currently, we can discuss the evolution of both traits based on phylogenetic relationships among members of Pentatomidae, although only partially. Yuan et al. (2015) conducted phylogenetic analyses based on mitogenomic data among species of the infraorder Pentatomomorpha, including some from Pentatomidae, and proposed the phylogenetic affinity of (Dolycoris $+($ Halyomorpha $+($ Eurydema + Nezara))). According to this phylogenetic relationship, our results indicate at least two evolutionary origins of either highly synchronized hatching with early egg feeding onset or non-synchronized hatching with late egg feeding onset. This supports the evolutionary association between the two traits. We should point out that synchronized hatching can evolve independently of a risk of sibling cannibalism: In moderately synchronized species (Pi. hybneri and Pl. stali), egg feeding does not start early enough to impose such a risk even on the eggs without a hatching response. As mentioned 
above, hatchlings of Pentatomidae aggregate close to their natal clutch to achieve protection against some risks like low temperature. It is possible that synchronized hatching accelerates formation of this aggregation in species in which hatchlings need rapid protection against the risks (Endo and Numata 2017).

Then, we suggest the following three possible hypotheses for explaining why the early egg feeding evolved in some of the study species, but not in the others. From this discussion, however, we exclude E. rugosum with no egg feeding.

The first hypothesis is that these species have different cost-benefit balances of killing and consuming viable sibling eggs; it is possible that the costs and benefits in some species differ from those in $H$. halys which we have discussed above. In this hypothesis, we assume that sibling egg cannibalism is adaptive in $H$. halys and $N$. viridula, but maladaptive in A. fieberi, D. baccarum, Pa. angulosa, Pi. hybneri, and Pl. stali. According to this hypothesis, hatchlings of the latter five species do not start egg feeding until viable siblings have finished hatching, so as not to kill their siblings. They do egg feeding because, in their natal clutch, there can be available nonviable eggs, such as unfertilized, abnormally developed, and parasitized eggs. Consumption of parasitized eggs has been reported in Oncopeltus spp. (Heteroptera: Lygaeidae) (Root and Chaplin 1976). We observed that, in the latter five species listed above, hatchlings started egg feeding after spending a motionless period close to the natal egg clutch, but in the former two species, hatchlings started egg feeding immediately. The motionless period possibly restricts the hatchlings to consuming nonviable eggs.

In the second hypothesis, cannibalism of viable eggs is adaptive not only in $H$. halys and $N$. viridula but also in the other five species. These five species may not start egg feeding early because, for example, they require a relatively long time after 
hatching until some organs essential for egg feeding, such as a stylet, become available. Differences in egg feeding abilities may possibly explain why egg feeding onset differs greatly even among these five species and why only E. rugosum shows no egg feeding.

In the third hypothesis, cannibalism of viable eggs is maladaptive in all the species, including H. halys and N. viridula, and egg feeding has evolved to utilize nonviable eggs within the natal clutch. According to this hypothesis, the highly synchronized hatching of $H$. halys and $N$. viridula was originally selected for some functions other than avoiding egg cannibalism. Then, the early egg feeding onset was selected because it was advantageous in competition among siblings for nonviable eggs. However, if this hypothesis is valid, alternative hypotheses are needed to explain the interspecific variation in temporal hatching patterns.

Detailed examination of the cost-benefit balance of cannibalism will provide a hint for gaining further insight into the association between the hatching patterns and the time of onset of egg feeding. Also, it is worthwhile to explore traits associated with early egg feeding in Pentatomidae and examine whether these traits favor cannibalism of viable sibling eggs. Among the species we used, N. viridula has the largest clutch size and $H$. halys also has a relatively large clutch size (see Materials and methods). Kiritani and Kimura (1966) revealed that the nymphal development of $N$. viridula does not improve even when the number of nymphs rises to more than ten, a much smaller number than its typical clutch size. Based on this report, we can consider that, if sibling egg cannibalism reduces nymphs in a larger clutch, it less negatively affects the benefits of group living. Therefore, a larger clutch size is one of the possible traits favoring the cannibalism.

In conclusion, the present study revealed that the cannibalistic tendency of 
hatchlings has possibly contributed to the evolution of the synchronized hatching in response to siblings in Pentatomidae. This finding deepens our knowledge that various social contexts with siblings can underlie the evolution of the synchronized hatching.

Acknowledgments We thank Kazuhiko Kuge and Masaho Haikata for assistance in collecting insects, Elizabeth Nakajima for linguistic corrections, and Yoshito Suzuki and Akira Mori for advice.

\section{Compliance with ethical standards}

Conflict of interest The authors declare that they have no conflict of interest.

Ethical approval All applicable international, national, and/or institutional guidelines for the care and use of animals were followed.

\section{References}

Acebes-Doria AL, Leskey TC, Bergh JC (2016a) Development and comparison of trunk traps to monitor movement of Halyomorpha halys nymphs on host trees. Entomol Exp Appl 158:44-53

Acebes-Doria AL, Leskey TC, Bergh JC (2016b) Host plant effects on Halyomorpha halys (Hemiptera: Pentatomidae) nymphal development and survivorship. Environ Entomol 45:663-670

Calizotti GS, Panizzi AR (2014) Behavior of first instar nymphs of Edessa meditabunda (F.) (Hemiptera: Pentatomidae) on the egg mass. Fla Entomol 97:277-280 
Colbert PL, Spencer RJ, Janzen FJ (2010) Mechanism and cost of synchronous hatching. Funct Ecol 24:112-121

Collie K, Kim SJ, Baker MB (2013) Fitness consequences of sibling egg cannibalism by neonates of the Colorado potato beetle, Leptinotarsa decemlineata. Anim Behav $85: 329-338$

Crespi BJ (1992) Cannibalism and trophic eggs in subsocial and eusocial insects. In: Elgar MA, Crespi BJ (eds) Cannibalism: ecology and evolution among diverse taxa. Oxford University Press, Oxford, pp 176-213

Dickinson JL (1992) Egg cannibalism by larvae and adults of the milkweed leaf beetle (Labidomera clivicollis, Coleoptera: Chrysomelidae). Ecol Entomol 17:209-218

Doody JS, Stewart B, Camacho C, Christian K (2012) Good vibrations? Sibling embryos expedite hatching in a turtle. Anim Behav 83:645-651

Eickwort KR (1973) Cannibalism and kin selection in Labidomera clivicollis (Coleoptera: Chrysomelidae). Am Nat 107:452-453

Endo J, Numata H (2017) Effects of embryonic responses to clutch mates on egg hatching patterns of Pentatomidae (Heteroptera). Physiol Entomol 42:412-417

Endo J, Takanashi T, Mukai H, Numata, H (2019) Egg-cracking vibration as a cue for stink bug siblings to synchronize hatching. Cur Biol 29:143-148

Elgar MA, Crespi BJ (1992) Cannibalism: ecology and evolution among diverse taxa. Oxford University Press, Oxford

Esquivel JF, Medrano EG (2014) Ingestion of a marked bacterial pathogen of cotton conclusively demonstrates feeding by first instar southern green stink bug (Hemiptera: Pentatomidae). Environ Entomol 43:110-115

Fréchette B, Coderre D (2000) Oviposition strategy of the green lacewing Chrysoperla 
rufilabris (Neuroptera: Chrysopidae) in response to extraguild prey availability. Eur J Entomol 97:507-510

Gomi T, Natsuyama M, Sasaki N (2015) Effects of sibling egg cannibalism on the development and survival of Chrysomela populi (Coleoptera: Chrysomelidae). Appl Entomol Zool 50:451-455

Hokyo N, Kiritani K (1962) Sampling design for estimating the population of the southern green stink bug, Nezara viridula (Pentatomidae, Hemiptera) in the paddy field. Jpn J Ecol 12:228-235

Kawada H, Kitamura C (1983) The reproductive behavior of the brown marmorated stink bug, Halyomorpha mista Uhler (Heteroptera: Pentatomidae) I. Observation of mating behavior and multiple copulation. Appl Entomol Zool 18:234-242

Kawai A (1978) Sibling cannibalism in the first instar larvae of Harmonia axyridis Pallas (Coleoptera, Coccinellidae). Kontyû 46:14-19

Kiritani K (1964) The effect of colony size upon the survival of larvae of the southern green stink bug, Nezara viridula. Jpn J Appl Entomol Zool 8:45-53

Kiritani K, Kimura K (1966) A study on the nymphal aggregation of the cabbage stink bug, Eurydema rugosum Motschulsky (Heteroptera: Pentatomidae). Appl Entomol Zool 1:21-28

Kiritani K, Nakasuji F, Hokyo N. (1966) The survival rate of eggs and larvae in relation to group size in the southern green stink bug, Nezara viridula L. Jpn J Appl Entomol Zool 10:205-211 [in Japanese with English abstract]

Kirk HM (1988) Cannibalism in a Chrysomelid beetle, Gastrophysa viridula.

Dissertation, University of Liverpool

Kutcherov D (2015) Egg-hatching synchrony and larval cannibalism in the dock leaf 
beetle Gastrophysa viridula (Coleoptera: Chrysomelidae). Zoology 118:433-438

Lee DH, Nielsen AL, Leskey TC (2014) Dispersal capacity and behavior of nymphal stages of Halyomorpha halys (Hemiptera: Pentatomidae) evaluated under laboratory and field conditions. J Insect Behav 27:639-651

Lockwood JA, Story RN (1985) Photic, thermic, and sibling influences on the hatching rhythm of the southern green stink bug, Nezara viridula (L.). Environ Entomol $14: 562-567$

Lockwood JA, Story RN (1986) Adaptive functions of nymphal aggregation in the southern green stink bug, Nezara viridula (L.) (Hemiptera: Pentatomidae). Environ Entomol 15:739-749

Michaud JP, Grant AK (2004) Adaptive significance of sibling egg cannibalism in Coccinellidae: comparative evidence from three species. Ann Entomol Soc Am $97: 710-719$

Mock DW, Parker GA (1998) The evolution of sibling rivalry. Oxford University Press, Oxford

Morimoto N (1965) Synchronization of hatching in an egg mass of the cabbage stink bug, Eurydema rugosa. Jpn J Appl Entomol Zool 9:125-126 [in Japanese]

Mukai H, Hironaka M, Tojo S, Nomakuchi S (2012) Maternal vibration induces synchronous hatching in a subsocial burrower bug. Anim Behav 84:1443-1448

Mukai H, Hironaka M, Tojo S, Nomakuchi S (2018) Maternal hatching synchronization in a subsocial burrower bug mitigates the risk of future sibling cannibalism. Ecol Evol 8:3376-3381

Nielsen AL, Hamilton GC, Matadha D (2008) Developmental rate estimation and life table analysis for Halyomorpha halys (Hemiptera: Pentatomidae). Environ 
Entomol 37:348-355

Nishide Y, Tanaka S (2016) Desert locust, Schistocerca gregaria, eggs hatch in synchrony in a mass but not when separated. Behav Ecol Soc 70:1507-1515

O'Connor RJ (1978) Brood reduction in birds: selection for fratricide, infanticide and suicide? Anim Behav 26:79-96

Osawa N (1992) Sibling cannibalism in the ladybird beetle Harmonia axyridis: fitness consequences for mother and offspring. Res Popul Ecol 34:45-55

Perry JC, Roitberg BD (2005) Games among cannibals: competition to cannibalize and parent-offspring conflict lead to increased sibling cannibalism. J Evol Biol $18: 1523-1533$

Polis GA (1981) The evolution and dynamics of intraspecific predation. Ann Rev Ecol Syst 12:225-251

Provine RR (1976) Eclosion and hatching in cockroach first instar larvae: a stereotyped pattern of behaviour. J Insect Physiol 22:127-131

Richardson ML, Mitchell RF, Reagel PF, Hanks LM (2010) Causes and consequences of cannibalism in noncarnivorous insects. Ann Rev Entomol 55:39-53

Root RB, Chaplin SJ (1976) The life-styles of tropical milkweed bugs, Oncopeltus (Hemiptera: Lygaeidae) utilizing the same hosts. Ecology 57:132-140

Spencer RJ, Thompson MB, Banks PB (2001) Hatch or wait? A dilemma in reptilian incubation. Oikos 93:401-406

Stevens L (1992) Cannibalism in beetles. In: Elgar MA, Crespi BJ (eds) Cannibalism: ecology and evolution among diverse taxa. Oxford University Press, Oxford, pp $256-276$

Stoleson SH, Beissinger SR (1995) Hatching asynchrony and the onset of incubation in 
birds, revisited. In: Power DM (ed) Current ornithology, vol 12. Springer, Boston, pp 191-270

Taylor CM (2016) Understanding the relationship between the brown marmorated stink bug, Halyomorpha halys (Stål), and its symbiont, Pantoea carbekii, with implications for stink bug management. Dissertation, University of Maryland

Todd JW (1989) Ecology and behavior of Nezara viridula. Ann Rev Entomol

$$
34: 273-292
$$

Warkentin KM (2011) Environmentally cued hatching across taxa: embryos respond to risk and opportunity. Integr Comp Biol 51:14-25

Warkentin KM, Caldwell MS (2009) Assessing risk: embryos, information, and escape hatching. In: Dukas R, Ratcliffe JM (eds) Cognitive ecology II: The evolutionary ecology of information processing and decision-making. University of Chicago Press, Chicago, pp 177-200

Woolf NK, Bixby JL, Capranica RR (1976) Prenatal experience and avian development: brief auditory stimulation accelerates the hatching of Japanese quail. Science 194:959-960

Yuan ML, Zhang QL, Guo ZL, Wang J, Shen YY (2015) Comparative mitogenomic analysis of the superfamily Pentatomoidea (Insecta: Hemiptera: Heteroptera) and phylogenetic implications. BMC Genom 16:460 


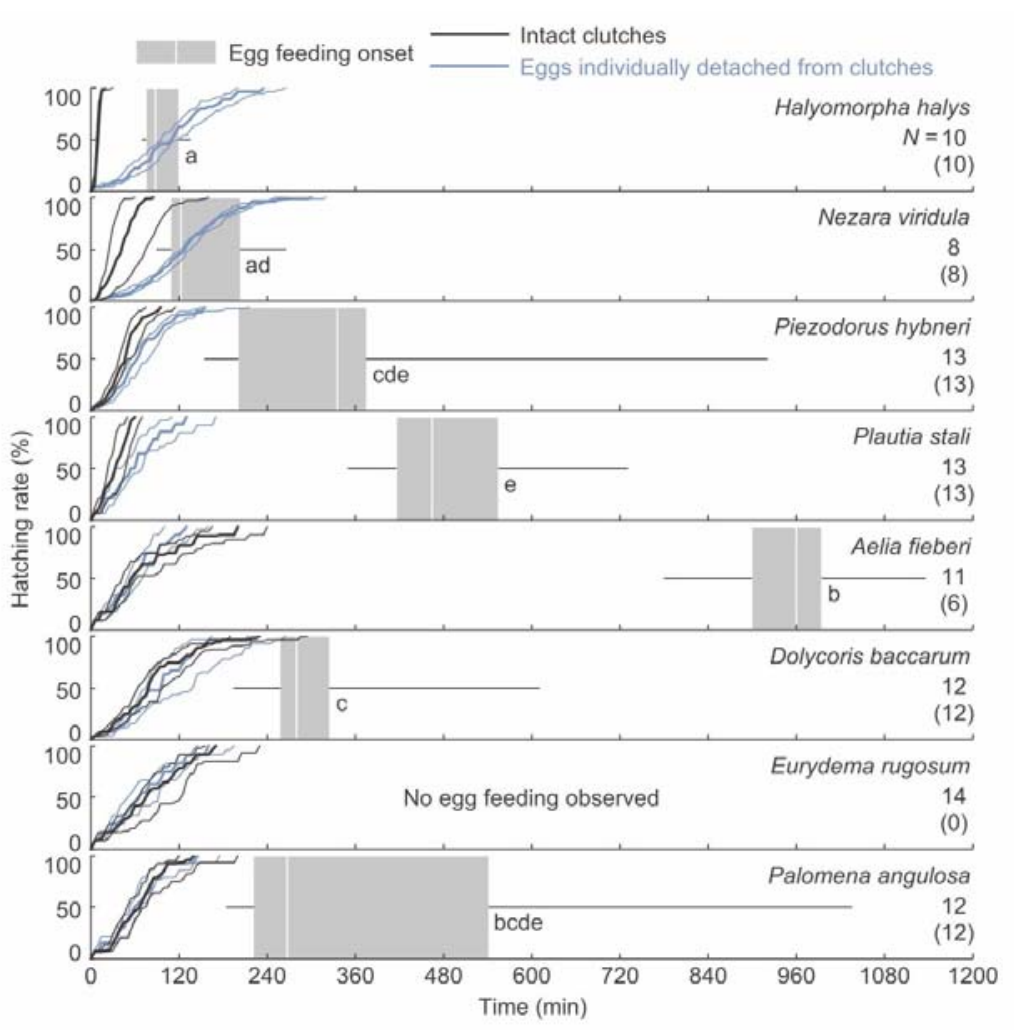

Fig. 1 The time of onset of egg feeding in eight species of Pentatomidae, shown with temporal hatching patterns of intact clutches or eggs individually detached from clutches of each species described by Endo and Numata (2017). Highly synchronized species, Halyomorpha halys and Nezara viridula; moderately synchronized species, Piezodorus hybneri and Plautia stali; and non-synchronized species, Aelia fieberi, Dolycoris baccarum, Eurydema rugosum, and Palomena angulosa. Box-and-whisker plots with different letters indicate statistically significant differences in the time of onset of egg feeding (Kruskal-Wallis test followed by Steel-Dwass post-hoc test: $P<$ 0.05). The numbers of observed egg clutches and those in which egg feeding was actually observed are shown under the species name (the latter are in parentheses). For the temporal hatching patterns, the median (bold line), the first quartile (lower thin line), and the third quartile (upper thin line) are shown for the rates of hatched eggs within a clutch at 5 min intervals 


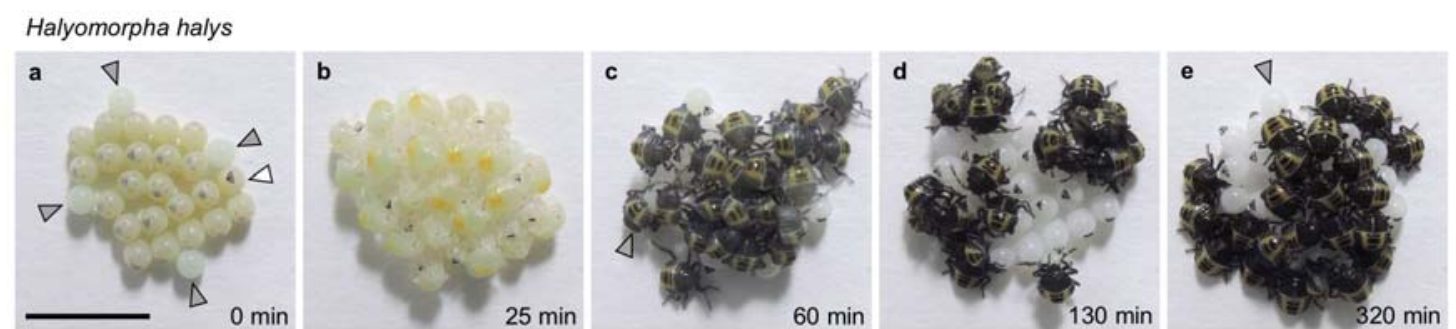

\begin{abstract}
Palomena angulosa
\end{abstract}
f

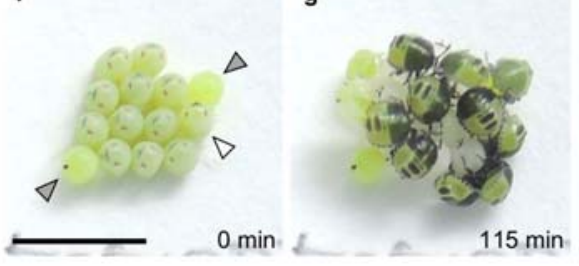

h

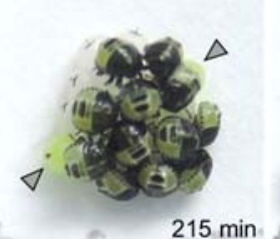

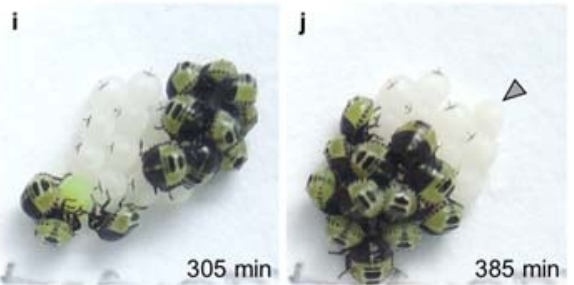

Fig. 2 Behavioral sequences after hatching in relation to egg feeding in Halyomorpha halys (a-e) and (f-j) Palomona angulosa. a, f The first egg has just started to hatch (white triangle). Some eggs with experimentally delayed development had been provided beforehand at the periphery of the clutches (gray triangles) so that the newly hatched nymphs could feed on them. b, $\mathbf{g}$ All the eggs of $H$. halys and Pa. angulosa have hatched except the provided eggs, and most of the nymphs have already emerged from the eggshells and started roaming on the natal clutches. $\mathbf{c}$ In the clutch of $H$. halys, one nymph has started holding one of the provided eggs (gray triangle) to eat it. d All the provided eggs have been subjected to egg feeding. All the nymphs are observed aggregating around the provided eggs. e Egg feeding has finished and the nymphs have settled in close to their natal clutch for the first time and become motionless. $\mathbf{h}$ In the egg clutch of Pa. angulosa, the provided eggs have not been eaten yet (gray triangle) but the nymphs have become motionless. $\mathbf{i}$ The nymphs have become active and aggregated around the provided eggs to eat them. $\mathbf{j}$ Egg feeding has finished and the nymphs have become motionless again. $\mathbf{e}, \mathbf{j}$ Gray triangle indicates a provided egg whose contents have been completely sucked out. Scale bar $=5 \mathrm{~mm}$ 


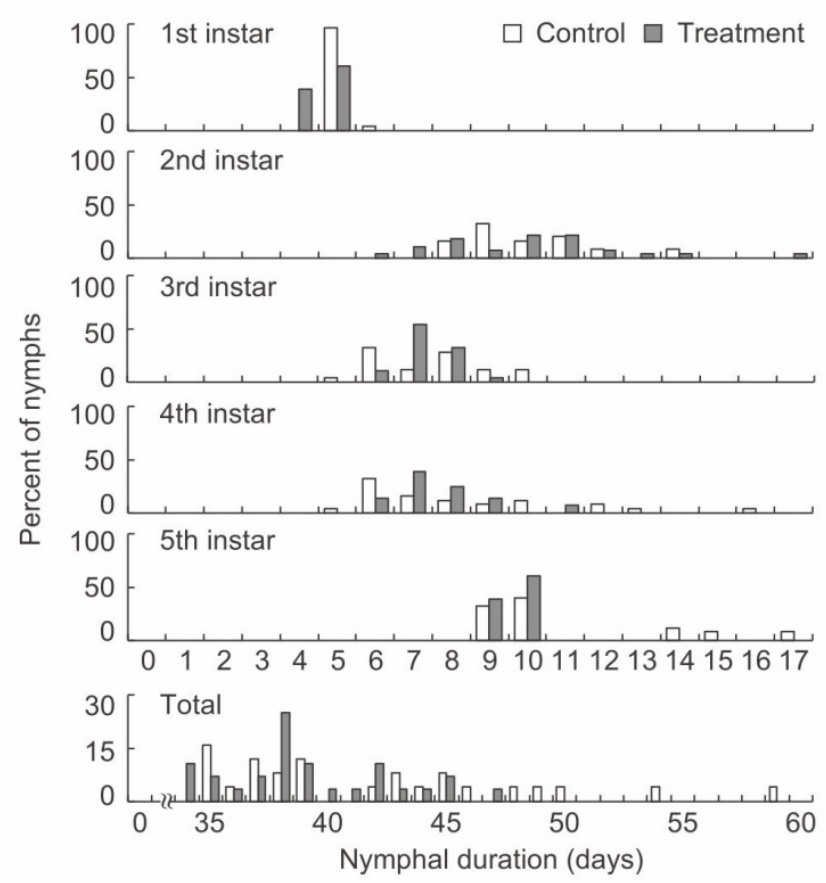

Fig. 3 Nymphal duration of Halyomorpha halys that fed on a single egg soon after hatching (treatment group: $N=25$ ) or no eggs (control group: $N=28$ ) shown for each instar and total nymphal period. Data on individuals that finally emerged as adults are shown 